\title{
BUT YOU DON'T HAVE TO LIVE HERE! RISK ASSESSMENT AND CONTAMINATED SITES: A CASE STUDY
}

\section{Alison Rutherford \\ Central Sydney Public Health Unit}

Mortlake is an inner-western suburb of Sydney, adjacent to the Parramatta River. The Mortlake Gasworks provided gas to most of Sydney for almost 100 years. After closure as a gasworks, the site remained heavily contaminated with waste typical of gasworks, such as tarry organic compounds. The cleanup of the 52-hectare site began in 1998, with the aim of selling the land for residential and commercial development. The NSW Environment Protection Authority (EPA) and the local council managed the statutory development approvals and remedial action plans under relevant legislation.

Human health risk assessments undertaken in relation to the site clean up included:

- baseline assessments to determine appropriate clean up criteria;

- occupational health surveys, including health screening of workers;

- modelling studies that assessed the risk to future apartment residents from residual tar in rock and groundwater;

- an assessment of the risks of tarry marine sediments to recreational users;

- an assessment of the risk of airborne contaminants leaving the site during the remediation.

The Central Sydney Public Health Unit (CSPHU) reviewed some of these assessments. This article describes the final assessment - the risk of airborne contaminants leaving the site during the remediation-in the context of the advantages and limitations of quantitative risk assessment and differing perceptions of what constitutes a 'risk to health'.

\section{MY STREET STINKS!!}

Residents living near the former gasworks began complaining of odours and health effects soon after the clean up began. Some residents reported immediate symptoms whenever the odours were present, such as headaches, itchy eyes, and nausea; other residents were concerned about the long-term health effects of odorous chemicals, particularly on their children's health. An independent environmental health consultant was contracted by the local council to investigate these symptoms. ${ }^{1}$

Many chemicals have different odour, irritative, and toxic thresholds. Some, such as benzene, are potentially toxic without any odour noticeable; others, such as naphthalene, are odorous at levels well below their toxic threshold. ${ }^{2}$
The consultant conducted a simple quantitative and qualitative risk assessment, involving:

- a comparison between the measured concentrations of contaminants at the site boundary and concentrations known to have a toxic effect (derived from toxicological studies);

- a detailed review of the risk associated with emissions of benzene from the site;

- interviews with affected residents and a qualitative assessment of their symptoms and potential causes.

The results demonstrated no risk from benzene emissions and suggested that the symptoms being experienced were not from direct chemical toxicity but rather that odours were initiating a physiological or olfactory-limbic response, both of which have been previously identified as mechanisms for the symptoms described. ${ }^{3}$ However, it was predicted that the symptoms would not abate until the odours were abated, and that people could become sensitised to odour and experience symptoms even when exposed to very low odour levels.

This risk assessment was important because:

- some of the chemicals on site were potentially carcinogenic;

- symptoms were validated by a recognised physiological mechanism;

- the site managers directed attention towards more active odour mitigation strategies (such as working in odorous areas only during suitable wind conditions and limiting the size of work surfaces);

- the EPA was provided with evidence to back up stronger regulatory action;

- new monitors with lower detection limits for benzene were introduced, due to the concern of some residents that the detection levels of benzene were slightly higher than the adopted annual average ambient standard $\left(20 \mathrm{~mm}^{3}\right.$ versus $\left.16 \mathrm{~mm}^{3}\right)$.

\section{MY NEIGHBOUR HAS CANCER: ISTHERE A LINK?}

Despite the findings of the risk assessment, some residents were concerned that recent cases of cancer in people living near the site were caused by the site remediation. These residents perceived that the number of people with cancer in their community was higher than in other areas. The CSPHU was asked to review the risk assessment and to conduct an epidemiological study of cancer in the area.

The CSPHU was aware that:

- local government maps of all cancer types from NSW Cancer Registry data, although crude measures, 
showed no significant difference between the local government area and the rest of NSW;

- there was no evidence that emissions from cleaning up the site could initiate or promote cancer (in contrast to any potential risk associated with past employment at the gasworks when operational);

- studies of incidence of disease in relatively small populations around industrial sites rarely produce definitive results.

In consultation with others, we reviewed the risk assessment and concluded that the assessment methodology was sound and there was no evidence of long term risk to health for residents living near the site. Rather than commence a lengthy and costly study without scientific justification, the CSPHU focused on communicating information about cancer, and about actual emission concentrations leaving the site, to concerned residents at a community consultation forum convened by the local council. The CSPHU received feedback that this consultation was helpful in alleviating the concerns of some people.

Following the implementation of better odour mitigation strategies, the number of odour complaints decreased but did not abate entirely. Other issues, such as dust and truck movements, became relatively more important to residents as the remediation progressed.

\section{DISCUSSION}

Concerns about risks tend to be heightened by risks that are:

- involuntary or imposed;

- man made;

- inescapable;

- controlled by parties outside the community;

- exotic or unfamiliar;

- the cause of dreaded health effects, such as cancer. ${ }^{4}$

The notion of something being a risk differs by age, gender, ethnicity, income, education, political persuasion, values, and perceived benefits of the issue at hand. ${ }^{5,6}$ Flynn postulates that "power, status, alienation, and trust are strong determinants of people's perception and acceptance of risk'. 5

Surveys in Australia have shown that people express substantial concern about exposure to chemicals, perceive chemicals as being predominantly dangerous, and make a conscious effort to avoid chemicals in their daily life. ${ }^{5}$ The threat of exposure to chemicals, while a site is being cleaned up, is almost a recipe for community concern.

Despite this concern, the evidence of serious health outcomes for residents exposed to environmental levels of chemicals is small, although there are methodological difficulties associated with these assessments, including small sample sizes, difficulty in quantifying exposure, and the lack of relevant biomarkers. NSW does have relatively strong environmental legislation, and a solid infrastructure to protect residential health during cleanups of former industrial sites. There is a paradox between the clean up of contaminated sites being perceived as dangerous and the lack of evidence establishing this danger.

In this case study, the perception of risk differed markedly between the stakeholders. Some of these perceptions can be characterised as follows:

- there are no toxic emissions leaving the site, so there are no real risks to health (environmental engineers);

- people are experiencing health effects, but they can be reassured that these will cause no long term biological damage (health agencies);

- the problem is not one of health risk but rather of nuisance (environmental agencies);

- the site poses much less risk to health now than it did when it was operating as a gasworks, and the current concern is a lot of fuss about nothing (residents);

- it is okay for the professionals to think there is no health risk, because they don't have to live here (residents);

- we are experiencing significant effects on our health, and no-one is taking our complaints seriously. In particular, psychological effects are being ignored (residents);

- the risks to health in the geographical area are so severe that the only option is to move away (residents).

Quantitative risk assessment, while an essential tool in the assessment of hazard, does not always address 'risk to health' as perceived by the community. In fact, critics of risk assessment argue that risk assessment, even more than other forms of scientific enquiry, purports objectivity while failing to acknowledge the inherent subjectivity of risk assessors. Scientists are not immune from perceiving risks according to their own worldview and this can frame the way that a risk assessment is conducted.

The underlying premise of these criticisms is that there is no universal definition of risk, and that risks may look very different to the people living near a site than they do to the risk assessors. Slovic argues that defining what is a risk is an exercise in power: 'Whoever controls the definition of risk controls the rational solution to the problem at hand. If risk is defined one way, then one option will rise as the most cost-effective or the safest or the best. If it is defined another way, perhaps incorporating qualitative characteristics and other contextual factors, one will likely get a different ordering of action solutions.' 


\section{WHAT'S A PUBLIC HEALTH UNITTO DO?}

It is clear that the gap between what a community wants to know and what a risk assessment will tell them needs to be bridged. Neutra suggests that there is a fundamental difference between traditional epidemiology and what he calls 'dump-site epidemiology', ${ }^{8}$ the investigation of health effects around waste disposal sites. In the latter, he argues, the decision to do a study is often made by the affected community and the audience really is that community, rather than other scientists. Rather than arguing that studies unlikely to produce statistically significant results should not be conducted, Neutra argues that affected people should be involved from the outset in specifying what answers the community wants and what level of uncertainty can be tolerated.

Where quantitative risk assessment or epidemiological studies are unlikely to resolve concern, some commentators have proposed that democratic models such as stakeholder-based decision-making should be used. In these models, prior to any investigation beginning, the focus is clearly on the values of stakeholders, important outcomes, and the probabilities of these outcomes. Citizen juries and consensus conferencing are two models that have been used in relation to environmental issues. Stakeholders may be asked to specifically consider the needs of the entire community.

It may be cost-effective and beneficial for health agencies to consider using such qualitative strategies to resolve environmental health issues. These have the advantage of not entering an argument about what is or is not a health risk, but rather focusing on outcomes that would be acceptable to all involved parties. While residents in this case study wanted to be certain that their future health was not at risk, they also just wanted the smells to go away.

One thing that health agencies should note is that the concept of 'community' is at times homogenising and misleading. It is impossible to alleviate the concerns of the entire community, and those people with the most local power are likely to get their concerns about risks addressed while other people remain unheard.

The use of alternative models to resolve environmental health issues, instead of or in addition to traditional risk assessment or epidemiological methods, is not a radical concept. It is what gets done in public health agencies daily in the name of risk communication and community consultation. What is different in the models above is that they involve more active input from the community and a relinquishing of some power from environmental health professionals and governments. They involve a specific shift from public health practitioners being the only ones who define what is 'risky' to health. This can be threatening, particularly when there are political and economic agendas associated with the definition of risk.

\section{CONCLUSION}

The meeting of the scientific paradigm of risk assessment with lay sensibilities of good health can lead to a traditional stand off between the rationality of science and the supposed irrationality of community sentiment. Quantitative risk assessment does not necessarily address threats to health as the community perceives them, although there is often pressure on health agencies to undertake 'health studies' of some sort, in the belief that this will provide objective, supportive evidence of the problems being experienced by the community.

The challenge for public health professionals is to combine the valuable data provided by the structured methodology of risk assessment (with its subjective assumptions) with qualitative approaches that recognise that risk is a contested term. The outcome should be meaningful results for all the stakeholders, including the people who live there.

\section{ACKNOWLEDGEMENTS}

The author would like to thank the following for their assistance and support: Mr David Donehue (AGL), URS Australia Pty Ltd, Dr David Douglas, Dr Leena Gupta, Mr Graham Burgess and Dr Michael Staff (Central Sydney Public Health Unit), Dr Vicky Sheppeard (NSW Department of Health), Ms Helen Davies, Mr Niall Johnstone and Mr John Sparkes (EPA), Dr Lillian Hayes, Canada Bay (previously Concord) Council, and the AGL Mortlake Community Liaison Committee.

\section{REFERENCES}

1. Douglas D. AGL Mortlake Rehabilitation Project Environmental Health Issues, 1 February 1999.

2. Ruth JH. Odor Thresholds and Irritant Levels of Several Chemical Substances: A Review. Journal of the American Industrial Hygiene Association 1986; 47(March).

3. Shusterman D. Odor-associated Health Complaints: Competing Explanatory Models. Chemical Senses 2001; 26: 339-343.

4. Starr G, Langley A, Taylor A. Environmental Risk Perception in Australia-A Research Report to the Commonwealth Department of Health and Aged Care. Adelaide: Centre for Population Studies in Epidemiology, South Australian Department of Human Services, 2000.

5. Flynn J, Slovi P, and Mertz CK. Gender, Race and perception of environmental health risks. Risk Analysis 1994; 14(6): 1101-8.

6. Alhakami AS, Slovic P. A psychological study of the inverse relationship between perceived risk and perceived benefit. Risk Analysis 1994; 14(6): 1085-96.

7. Slovic P. Trust, Emotion, Sex, Politics and Science: Surveying the Risk Assessment Battlefield. Risk Analysis 1999; 19(4): 689-701.

8. Neutra RR. Epidemiology for and with a Distrustful Community. Environ Health Perspect 1985; 62: 393-975. W 